\title{
Drug therapies in chronic heart failure: a focus on reduced ejection fraction
}

\author{
Authors: Helena Bolam, ${ }^{A}$ Geraint Morton ${ }^{B}$ and Paul R Kalra ${ }^{C}$
}

There are multiple evidence-based drug treatments for chronic heart failure (HF), both disease-modifying agents and those for symptom control. The majority of the evidence base supports drugs used in $\mathrm{HF}$ with reduced left ventricular ejection fraction. The mainstay of disease modification involves manipulation of neurohormonal activation that occurs in HF. In addition to established angiotensin-converting enzyme inhibitors, beta blockers and mineralocorticoid receptor antagonists (MRAs), newer agents are now available such as the angiotensin receptor neprilysin inhibitors. Achieving the optimal drug regimen is complex and best performed by a specialist heart failure team. We aim to provide a comprehensive overview of contemporary drug therapies in chronic heart failure, as well as practical guidance for their use. There is a focus on treating patients with challenging comorbidities such as hypotension and chronic kidney disease (CKD), where a thorough understanding of drug therapy is essential. Multiple trials assessing the benefits of new therapies in $\mathrm{HF}$, such as intravenous iron, are also ongoing.

\section{Introduction}

Heart failure (HF) is a clinical syndrome with typical signs and symptoms that include dyspnoea, fatigue, peripheral oedema and raised jugular venous pressure. It is caused by many conditions including ischaemic heart disease (IHD), hypertension, valvular heart disease and primary cardiomyopathies all of which result in functional and/or structural cardiac abnormalities. Ischaemic heart disease is the commonest cause in the western world. ${ }^{1,2}$ Heart failure is common, the Rotterdam Study reported a prevalence of $0.9 \%$ in subjects aged $55-64$ years, rising to $17.4 \%$ in those aged $\geq 85$. $^{3}$ The lifetime risk for 55 -year-olds was $33 \%$ for men and $29 \%$ for women. Heart failure is responsible for $1-2 \%$ of western healthcare systems budgets and inevitably will rise with an ageing population. ${ }^{4}$ The bulk of cost relates to frequent and lengthy hospitalisations. While prognosis has improved, it still

Authors: A cardiology specialist registrar, Department of Cardiology, Queen Alexandra Hospital, Portsmouth Hospitals NHS Trust, Portsmouth, UK; ${ }^{B}$ consultant cardiologist, Department of Cardiology, Queen Alexandra Hospital, Portsmouth Hospitals NHS Trust, Portsmouth, UK; ' Consultant cardiologist, Department of Cardiology, Queen Alexandra Hospital, Portsmouth Hospitals NHS Trust, Portsmouth, UK remains poor - recent UK data show in-hospital mortality rates of $8.9 \%$, median length of stay at 9 days and of those surviving to discharge $26.7 \%$ die within a year. ${ }^{5}$

The mainstay of treatment for $\mathrm{HF}$ is drug therapy. By promptly identifying patients with HF and commencing evidence-based therapies it is possible to markedly improve morbidity and mortality. Patients with HF have typically been grouped into those with preserved or reduced left ventricular (LV) systolic function. Recent guidelines have further divided patients according to LV ejection fraction (EF, LVEF): HF with reduced $\mathrm{EF}$ (HFrEF) $-\mathrm{EF}<40 \%$, HF with preserved $\mathrm{EF}$ (HFpEF)-EF $\geq 50 \%$, and the relatively new term $\mathrm{HF}$ with mid-range $\mathrm{EF}$ (HFmrEF) - EF 40-9\%. ${ }^{6}$ The unifying criteria are the presence of symptoms, with or without signs of HF. Additional characteristics are required to make the diagnosis of HFpEF, including raised natriuretic peptides and relevant structural heart disease (eg left ventricular hypertrophy) and/or markers of diastolic dysfunction. Categorisation of patients with HF according to LVEF is clinically important due to different underlying aetiologies, comorbidities and evidence base for treatment. The evidence that drug therapy improves prognosis (markedly reduced hospitalisation and mortality) is overwhelming for patients with HFrEF. In contrast, there are no clear data to date that drugs improve outcomes for patients with HFpEF (or HFmrEF). The prime focus is of this article is therefore therapies for HFrEF. However, in practice, many of the drugs used in HFrEF are also the mainstay of treatments for HFpEF (and HFmrEF) where they are used to treat symptoms and modify risk factors for $\mathrm{HF}$ such as hypertension. The inclusion of HFmrEF is aimed at stimulating research for this group, in order to identify the underlying pathophysiology as well as effective treatment options for this group. However, it may actually create a degree of clinical uncertainty. It is also important to note that in addition to drug therapy all patients with HF are also considered for other evidence based interventions where applicable, such as device therapy (implantable cardioverter defibrillators, cardiac resynchronisation therapy) and cardiac rehabilitation.

\section{Established prognostic therapy in HFrEF}

Chronic activation of neurohormonal pathways, in particular the renin-angiotensin-aldosterone axis and sympathetic nervous system, play a central role in the progression of HF. ${ }^{7}$ These activated neurohormonal systems contribute to adverse haemodynamics such as peripheral vasoconstriction with increased afterload and sodium and water retention with subsequent increase in preload. In addition, angiotensin II and 
aldosterone are thought to directly contribute to myocardial and renal fibrosis. The incremental use of neurohormonal antagonists improves survival for patients with HFrEF and are recommended for the treatment of every patient, unless contraindicated or not tolerated. These drugs should be considered as 'diseasemodifying', with benefits on mortality, hospitalisation, quality of life (QoL) and markers of left ventricular function. The recommendations are to start at low dose with careful and gradual uptitration.

It is 30 years since the first randomised 'mega trial' (CONSENSUS) established the importance of angiotensinconverting enzyme inhibitors (ACEi) in $\mathrm{HFrEF}^{8}$ Further trials confirmed reductions in mortality and morbidity cementing the place of ACEi as first-line therapy. ${ }^{9}$ These drugs inhibit the activity of angiotensin-converting enzyme and therefore prevent the formation of angiotensin II from angiotensin I. This results in natriuresis and diuresis and a reduction in arterial blood pressure and thereby afterload. The recommended starting and target doses of a number of ACEi with an evidence base in HFrEF are detailed in Table $1 .{ }^{10}$ Although it results in an increase in drug burden, a twice-daily ACEi regime (at least for some drugs) may be more effective than once-daily in terms of neurohormonal modification. ${ }^{11}$ Monitoring of renal function and electrolytes is important (discussed here later).

Angiotensin receptor blockers (ARBs) are considered in patients who are intolerant of ACEis, primarily due to cough; the effect on renal function is similar. They block the action of angiotensin II by preventing it from binding to angiotensin receptors. Candesartan (CHARM study) decreased cardiovascular mortality and morbidity, while valsartan showed a reduction in the combined primary endpoint of mortality and morbidity mainly by reducing HF hospitalisations. ${ }^{12,13}$ The CHARM study suggested additive benefit of ARB to ACEi. ${ }^{14}$ However, due to the risk of hypotension, hyperkalaemia and renal dysfunction when combining ACEis and ARBs, and the recommendation for more routine use of mineralocorticoid receptor antagonists (MRAs) this is no longer

\begin{tabular}{|c|c|c|c|}
\hline Class & Drug name & Starting dose & Target dose \\
\hline \multirow[t]{4}{*}{ ACEi } & Captopril & $6.25 \mathrm{mg} \mathrm{tds}$ & $50 \mathrm{mg}$ tds \\
\hline & Enalapril & $2.5 \mathrm{mg} \mathrm{bd}$ & $10-20 \mathrm{mg} \mathrm{bd}$ \\
\hline & Lisinopril & $2.5-5 \mathrm{mg}$ od & $20-35 \mathrm{mg}$ od \\
\hline & Ramipril & $1.25 \mathrm{mg} \mathrm{bd}$ & $5 \mathrm{mg} \mathrm{bd}$ \\
\hline \multirow[t]{2}{*}{ ARB } & Candesartan & $4 \mathrm{mg}$ od & $32 \mathrm{mg}$ od \\
\hline & Valsartan & $40 \mathrm{mg} \mathrm{bd}$ & $160 \mathrm{mg} \mathrm{bd}$ \\
\hline \multirow[t]{3}{*}{ Beta blockers } & Bisoprolol & $1.25 \mathrm{mg} \mathrm{od}$ & $10 \mathrm{mg}$ od \\
\hline & Carvedilol & $3.125 \mathrm{mg} \mathrm{bd}$ & $25 \mathrm{mg} \mathrm{bd}$ \\
\hline & Nebivolol & $1.25 \mathrm{mg} \mathrm{od}$ & $10 \mathrm{mg}$ od \\
\hline \multirow[t]{2}{*}{ MRA } & Eplerenone & $25 \mathrm{mg}$ od & $50 \mathrm{mg}$ od \\
\hline & Spironolactone & $25 \mathrm{mg} \mathrm{od}$ & $25 \mathrm{mg}$ od \\
\hline
\end{tabular}

$\mathrm{ACE} \mathrm{i}=$ angiotensin converting enzyme inhibitor; $\mathrm{ARB}=$ angiotensin receptor blocker; $b d$ = twice daily; MRA = mineralocorticoid receptor antagonist; od = once daily; tds = three times a day advocated. ${ }^{6}$ In contrast, Aliskiren, a direct renin inhibitor, was of no benefit in the ASTRONAUT trial and is not recommended. ${ }^{15}$

Despite early scepticism, the beneficial effects of beta blockade in HFrEF are well documented. Beta blockers bind to beta-adrenoceptors and block the binding of adrenaline and noradrenaline to these receptors thereby inhibiting the effects of the sympathetic nervous system. Key studies since the 1990s have shown additive reduction in mortality and morbidity when a beta blocker is given to symptomatic patients with reduced LVEF. This was seen with carvedilol, controlled-release metoprolol (unavailable in UK), bisoprolol and nebivolol, as shown in the COPERNICUS, MERIT-HF, CIBIS-II and SENIORS trials respectively. ${ }^{16-19}$ Data comparing beta blockers are very limited. The COMET trial found carvedilol was superior to (short-acting) metoprolol in reducing all-cause mortality, ${ }^{20}$ though this may have been affected by low metoprolol dose. In the SENIORS study, nebivolol did not reduce all-cause mortality (secondary endpoint) but, in contrast to other studies, did include patients with HFpEF ( $36 \%$ of subjects). ${ }^{17}$ Beta blockers should not be commenced during a heart failure exacerbation (decompensation) because of negative inotropic effects, but should be initiated when the patient is euvolaemic. ${ }^{21}$ Patient and carer education is crucial; some feel slightly worse after beta blocker initiation but in general this resolves fairly quickly if they persevere. While no study has compared different heart rate targets, the heart rate achieved at day 30 in SHIFT was predictive of outcome - best seen around 60 beats per minute (bpm). ${ }^{22}$ It is the authors' opinion that optimising beta blocker dose (and ivabradine where required) to achieve a target resting heart rate of around $60 \mathrm{bpm}$ in sinus rhythm is appropriate (assuming no adverse symptoms). At least part of the benefit of beta blockade may be explained by heart rate reduction. ${ }^{23}$ Following optimisation of ACEi and beta blocker, in patients with HFrEF who remain symptomatic, a MRA (spironolactone or eplerenone) should be added (Fig 1). Mineralocorticoid receptor antagonists antagonise the actions of aldosterone by blocking the mineralocorticoid receptor. While MRAs have diuretic effects and may help achieve optimal fluid balance, key benefits are on reduction of mortality and HF hospitalisations (likely from reducing risk of hypokalaemia and adverse myocardial and renal parenchymal fibrosis from aldosterone excess). ${ }^{24-26}$ Spironolactone was evaluated in patients with severe symptoms and $\mathrm{HFrEF}^{25}$ while eplerenone showed benefit in patients with severe LV systolic dysfunction and relatively mild symptoms, ${ }^{24}$ as well as in post myocardial infarction $\mathrm{HF}^{27}$ Spironolactone can result in painful gynaecomastia and other dose-dependent sexual side effects (due to affinity for progesterone, androgen and glucocorticoid receptors); if these occur it seems intuitive to switch to eplerenone, where these side effects are less common. ${ }^{28}$ The doses of spironolactone and eplerenone are not interchangeable; in clinical practice a higher dose of eplerenone is often required to achieve a similar effect to $25 \mathrm{mg}$. This may be due to a lower binding affinity of eplerenone to the mineralocorticoid receptor. ${ }^{29}$

\section{Newer agents with prognostic benefit}

Elevated heart rate has consistently been associated with adverse prognosis in patients with $\mathrm{HF}^{30,31}$ Not all patients with HFrEF tolerate beta blockers or achieve doses high enough to adequately reduce resting heart rate. ${ }^{32}$ Ivabradine is an $I_{f}$ ('funny' channel) inhibitor acting on the sinoatrial node to slow heart rate 

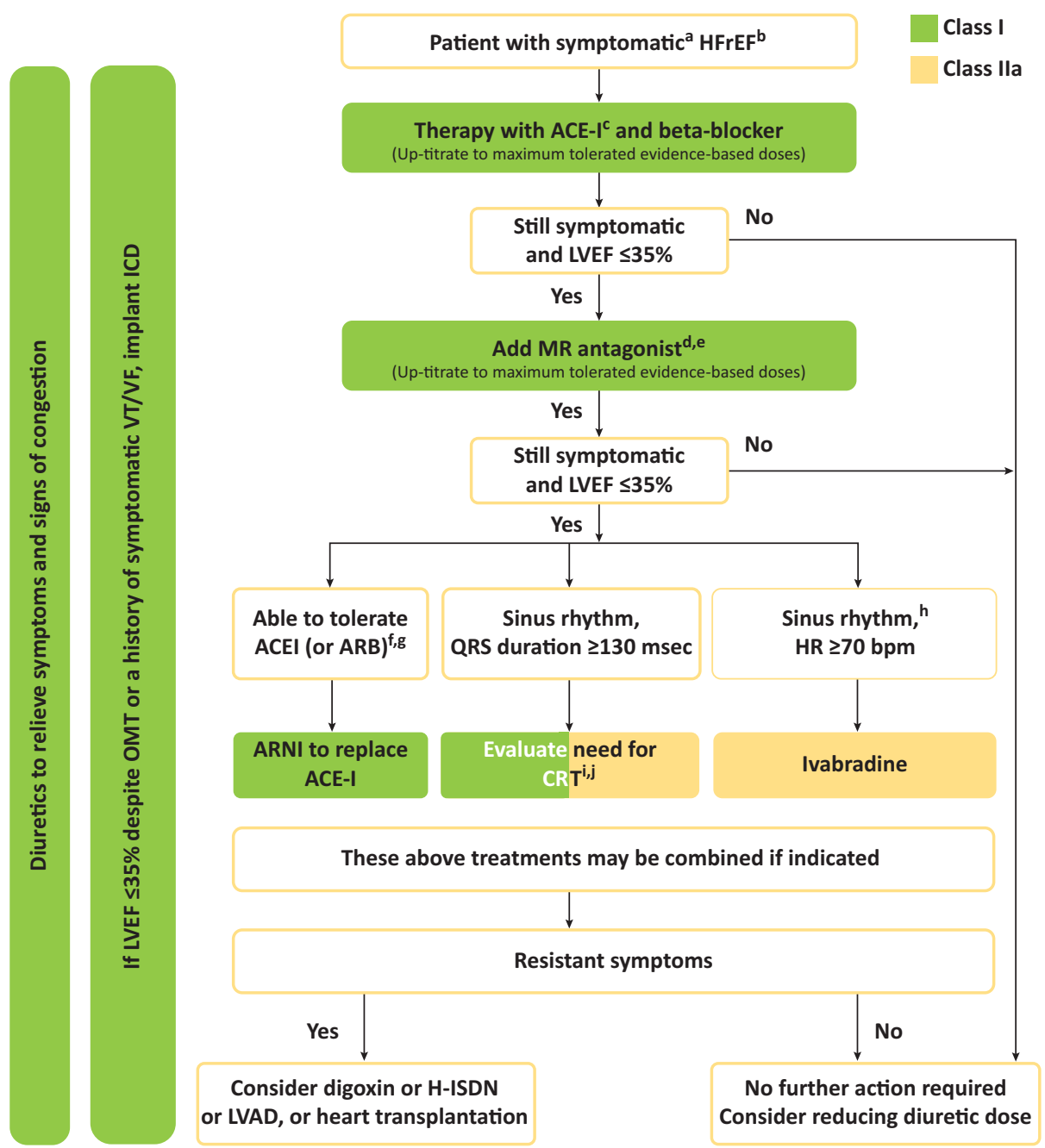

Fig 1. Therapeutic algorithm for a patient with symptomatic heart failure with reduced ejection fraction. Reproduced with permission. ${ }^{1}$ Green indicates a class I recommendation; yellow indicates a class IIa recommendation. ACEi = angiotensinconverting enzyme inhibitor; $A R B=$ angiotensin receptor blocker; $\mathrm{ARNI}=$ angiotensin receptor neprilysin inhibitor; $\mathrm{BNP}=\mathrm{B}$-type natriuretic peptide; $\mathrm{CRT}=$ cardiac resynchronisation therapy; $\mathrm{HF}=$ heart failure; $\mathrm{HFrEF}=$ heart failure with reduced ejection fraction; $\mathrm{H}$-ISDN = hydralazine and isosorbide dinitrate; $\mathrm{HR}=$ heart rate; $\mathrm{ICD}=$ implantable cardioverter defibrillator; $\mathrm{LBBB}=$ left bundle branch block; $L \mathrm{VAD}=$ left ventricular assist device; $\mathrm{LVEF}=$ left ventricular ejection fraction; $\mathrm{MR}=$ mineralocorticoid receptor; $N T$ proBNP = N-terminal pro-B type natriuretic peptide; NYHA = New York Heart Association; OMT = optimal medical therapy; $\mathrm{VF}=$ ventricular fibrillation; $\mathrm{VT}=$ ventricular tachycardia. ${ }^{a}$ Symptomatic $=$ NYHA Class II-IV. ${ }^{b} \mathrm{HFrEF}=\mathrm{LVEF}<40 \%$. ${ }^{\mathrm{c} I f}$ ACE inhibitor not tolerated/contraindicated, use ARB. ${ }^{\mathrm{d}}$ If MR antagonist not tolerated/contraindicated, use ARB. ${ }^{e}$ With a hospital admission for $\mathrm{HF}$ within the last 6 months or with elevated natriuretic peptides (BNP $>250 \mathrm{pg} / \mathrm{mL}$ or NTproBNP $>500 \mathrm{pg} / \mathrm{mL}$ in men and $750 \mathrm{pg} / \mathrm{mL}$ in women). ${ }^{\mathrm{f}}$ With an elevated plasma natriuretic peptide level (BNP $\geq 150 \mathrm{pg} / \mathrm{mL}$ or plasma NT-proBNP $\geq 600 \mathrm{pg} / \mathrm{mL}$, or if HF hospitalisa-

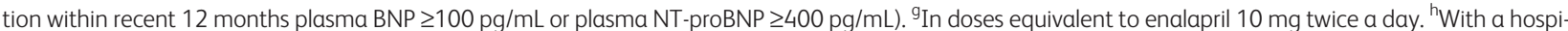
tal admission for $\mathrm{HF}$ within the previous year. ${ }^{\mathrm{C} C R T}$ is recommended if $\mathrm{QRS} \geq 130 \mathrm{~ms}$ and LBBB (in sinus rhythm). ${ }^{\mathrm{j}} \mathrm{CRT}$ should/may be considered if QRS $\geq 130 \mathrm{~ms}$ with non-LBBB (in a sinus rhythm) or for patients in AF provided a strategy to ensure bi-ventricular capture in place (individualised decision).

(therefore only useful in sinus rhythm). The SHIFT study showed benefit on the combined endpoint of cardiovascular death and $\mathrm{HF}$ hospitalisation when ivabradine was added to maximum tolerated doses of beta blockers as well as ACEi/ARB and MRA (mainly due to reduction in HF admissions). ${ }^{22}$ The National Institute for Health and Care Excellence (NICE) approved its use for patients with HFrEF and resting heart rate $\geq 75$ bpm after beta blocker optimisation. ${ }^{26}$ Ivabradine is generally well tolerated, without detrimental effect on blood pressure and is associated with improvements in QoL. ${ }^{33}$
Angiotensin receptor neprilysin inhibitors (ARNIs) are a new class of drugs, the first being a combination of valsartan (ARB) and sacubitril (neprilysin inhibitor). The latter augments beneficial counter-regulatory effects of vasodilatory peptides including the natriuretic peptide family. The PARADIGM-HF clinical trial in patients with HFrEF showed sacubitril/valsartan was superior to enalapril at reducing the risk of cardiovascular death and hospitalisation from HF. The trial was stopped early because of significant survival benefit seen with sacubitril/ valsartan. The relative risk reduction of cardiovascular death/ 
hospitalisation from HF was highly significant at $20 \%$. $^{34}$ Although direct comparisons are not possible, the magnitude of benefit of changing an ACEi to an ARNI was similar to that observed when comparing ACEi to placebo ${ }^{35}$ or when adding in beta-blocker therapy. ${ }^{16}$ Although symptomatic hypotension was more common in those taking sacubitril/valsartan, there was no difference in the rates of discontinuation between groups.

In 2016, NICE published criteria for use of sacubitril/ valsartan in HFrEF: New York Heart Association class II-IV, LVEF $\leq 35 \%$ established on stable dose of ACEi or ARB. ${ }^{36}$ The European Society of Cardiology (ESC) guidelines have an IB recommendation for sacubitril/valsartan for patients with HFrEF who remain symptomatic despite treatment with ACEi, beta blocker and MRA. ${ }^{6}$ When ACEi has been standard of care, it must be stopped for at least 36 hours prior to commencing sacubitril/ valsartan. Monitoring of renal function is the same as for ACEi and $A R B{ }^{36}$

\section{Diuretics}

Diuretics are used to reduce symptoms and signs of congestion, and the aim is to render the patient euvolaemic using the minimum dose. A meta-analysis of randomised controlled trials involving loop or thiazide diuretics showed improvement in exercise capacity, reduction in risk of disease progression and reduction in risk of death, although the latter was based on data from small trials. ${ }^{37}$ Recently, a retrospective study showed a reduction in hospital and 1-year mortality with more intensive diuretic use (as well as improved use of evidence-based therapies via a multidisciplinary team approach). ${ }^{38}$ In terms of choice of oral loop diuretics, furosemide has greater variability in absorption, but no study has shown significant difference in outcomes between furosemide and bumetanide. ${ }^{39-41}$

When patients present with decompensated HF ie with marked fluid excess, a period of intravenous diuretic therapy is generally warranted. Many such patients have chronic kidney disease (CKD) and often the decompensation is associated with worsening renal function or acute kidney injury (AKI). Achievement of euvolaemia is fundamental and many patients require high dose intravenous loop diuretics and for some additional thiazide diuretics and MRA (progressive nephron blockade). It is important to remember that in general it is congestion per se, as opposed to the diuretics, that has driven the deterioration in renal function. ${ }^{42}$ Data, albeit commonly observational, suggest that adverse prognosis is impacted more by the ongoing presence of oedema as opposed to a deterioration in renal function during hospitalisation. ${ }^{43}$

\section{Older therapies with some prognostic benefit}

The use of a combination of hydralazine and isosorbide dinitrate is given an IIB recommendation in the ESC guidelines for specific situations. ${ }^{6}$ Data on this drug combination are limited to a few small studies in specific patient subgroups, mainly before standard therapy with ACEi and beta blockers was established. There is some evidence of additional benefit when added to standard therapy in black patients with symptomatic HFrEF and dilated $\mathrm{LV}^{44}$ The combination may also be considered in patients who are intolerant of ACEis/ARBs (generally for very severe CKD) but the evidence for this is based on the Veterans Administration
Cooperative Study, involving male patients with HF who were only taking digoxin and diuretics. ${ }^{45}$

Digoxin reduced the rate of hospitalisations in patients with HF in sinus rhythm in the Digitalis Study, but did not reduce mortality. ${ }^{46}$ However, post hoc analysis of the DIG trial showed mortality benefit with low dose digoxin in very high risk groups. ${ }^{47}$ Current guidelines (Fig 1) only advocate the use of digoxin in HFrEF and sinus rhythm in selected cases (in our experience this might include patients with symptomatic hypotension merely tolerating low doses of neurohormonal antagonists).

\section{Drugs with little or no prognostic benefit}

The relationship of cholesterol to outcomes in chronic diseases, such as HF, is complex. Large randomised studies have shown no benefit of statins in patients with established HFrEF, irrespective of aetiology. ${ }^{48,49}$ However, in the PROVE IT-TIMI 22 study, intensive statin therapy with atorvastatin $80 \mathrm{mg}$ reduced the risk of hospitalisation for HF following acute coronary syndrome as compared to moderate dose statin (pravastatin $40 \mathrm{mg})^{50}$

Use of $n-3$ polyunsaturated fatty acids ( $n-3$ PUFAs) have level IIbB recommendation in the ESC guidelines. ${ }^{6}$ The GISSI-HF trial showed a small benefit in decreasing mortality and hospital admissions when n-3 PUFAs were added to standard care. ${ }^{51}$ Therefore, while $n-3$ PUFAs may be considered in symptomatic patients the magnitude of absolute benefit is limited.

Calcium channel blockers do not provide benefit in HFrEF and some may increase the risk of worsening HF and hospitalisations. ${ }^{52,53}$ If a patient with $\mathrm{HF}$ requires further antihypertensive or antianginal therapy, a long-acting dihydropyridine, such as amlodipine is considered safe. ${ }^{54}$

\section{Considerations in specific situations}

\section{Hypotension}

Many prognostically beneficial drugs for HF lower blood pressure. It is vital that all involved in care understand that blood pressure reduction is not the primary reason for their use. The precise blood pressure at which one should reduce drug doses will vary between patients; significant symptomatic hypotension is generally the driving force. When symptomatic hypotension limits drug optimisation, it is generally considered preferable to have patients on some of each of ACEi, beta blocker and MRA, as opposed to a high dose of a single agent.

\section{Renal function}

Chronic kidney disease is common in patients with HF and independently associated with adverse prognosis. ${ }^{55}$ Prognostically beneficial drugs in HFrEF such as ACEi, ARB, MRA and ARNIs influence haemodynamics and renal blood flow. However, they are not nephrotoxic. During initiation and uptitration it is common to see some increase in serum creatinine or drop in estimated glomerular filtration rate. In general, the risk of stopping or reducing the dose is likely to be of greater detriment to prognosis than a modest increase in serum creatinine. ${ }^{56}$ In contrast, in patients with HFpEF there is no convincing evidence that ACEi, ARB or MRA alter prognosis. As such if renal function deteriorates significantly with their use consider stopping them. 


\section{Atrial fibrillation}

This is a common comorbidity and a key consideration is whether the patient should receive anticoagulation. In patients where rhythm control is pursued amiodarone is the antiarrhythmic of choice (ideally with beta blockers). ${ }^{6}$ Beta blockers are generally used for rate control, alone or in combination with digoxin. There is controversy as to whether beta blockers are associated with prognostic benefit in $\mathrm{HFrEF}$ and atrial fibrillation. ${ }^{57}$ In a patient presenting with decompensated $\mathrm{HF}$ and uncontrolled atrial fibrillation, initial rate control with digoxin and offloading is preferential. Once stabilised, beta blockade can be added. Resting target heart rate for patients with atrial fibrillation and HFrEF should be more lenient than for those in sinus rhythm, due at least in part the risk of potential bradycardia-induced arrhythmias. ${ }^{58,59}$ The authors generally look for an apical resting rate of around 70-90 bpm.

\section{Heart failure exacerbation}

Diuretic therapy to achieve euvolaemia has been discussed. It is preferential to continue with other drugs such as ACEi or beta blockers at usual dose during the exacerbation if possible. ${ }^{60,61}$ If these drugs are reduced or withheld, this must be considered as a temporary adjustment. Prior to discharge, all drugs should be restarted, with plans in place to reoptimise under outpatient HF services. When a clinician is contemplating stopping a disease modifying drug for $\mathrm{HFrEF}$, it is vital to consider this akin to stopping chemotherapy for cancer. The adverse impact on prognosis may actually be greater in HF and patients should be involved in the final decision making.

\section{Elderly patients}

Patients often have multiple comorbidities, and polypharmacy is the norm. For many, QoL is more important than longevity. ${ }^{62}$ Involvement of patients in informed decision making and simplification of drug regimens (including stopping unnecessary drugs) should be standard care. Measuring postural blood pressures and electrocardiogram monitors may be useful to aid in this process. It may be more important to focus on symptoms (for example with diuretics and rate control) rather than on prognostically beneficial medications.

\section{Chronic obstructive pulmonary disease}

Beta blockers are not contraindicated in patients with chronic obstructive pulmonary disease. ${ }^{63}$ Patients with cor pulmonale should be treated according to their LVEF but frequently tolerate drugs poorly due to hypotension and have a poor prognosis. ${ }^{64}$

\section{Systems of care for optimising drug therapy}

Outcomes for both inpatients ${ }^{5}$ and outpatients ${ }^{65}$ are improved when patients are managed by a multidisciplinary heart failure team. Although the teams provide multifaceted care a very important role of this team is optimisation of drug therapy.

\section{The future}

Iron deficiency is common in $\mathrm{HF}$ and associated with worse prognosis. ${ }^{66}$ Several studies have shown that intravenous iron in patients with $\mathrm{HF}$ and iron deficiency results in improved QoL, exercise capacity and symptoms. ${ }^{67-69}$ None were powered to assess mortality or hospitalisation. A number of ongoing studies are addressing this and include the UK based 'The intravenous iron treatment in patients with heart failure and iron deficiency [IRONMAN] study'.70

The ongoing GALACTIC-HF trial is assessing whether treatment with omecamtiv mecarbil (a cardiac-specific myosin activator) is superior to placebo in reducing the risk of cardiovascular death or HF events in subjects with chronic HFrEF. $^{71}$

\section{Drug therapies in HFpEF/HFmrEF}

There are currently no evidence-based treatments available for these groups that significantly affect mortality. Although traditionally HFpEF was thought to be caused solely by left ventricular diastolic dysfunction, it is now understood that there are multiple heterogenic aetiologies such as systemic and pulmonary vascular dysfunction, as well as neurohormonal activation, which makes treatment of this group of patients more challenging. ${ }^{72,73}$ Consequently, the mainstay of management is to alleviate symptoms. Diuretics and exercise training programmes have been shown to improve exercise capacity and QoL. ${ }^{74-77}$

Many of the drug therapies used in HFrEF have not been shown to be beneficial in HFpEF. ${ }^{78-80}$ New agents are being trialled. There is an ongoing randomised placebo-controlled trial to determine whether vericiguat (a soluble guanylate cyclase stimulator) increases the time to cardiovascular death or HF hospitalisation in patients with HFpEF. It has already been shown to improve QoL. ${ }^{81}$ It is hoped future research may yield concrete recommendations for patients with HFmrEF. While specific data are awaited, many clinicians extrapolate trial results from patients with LVEF $<40 \%$ and use ACEi, beta blockers and MRA in patients with LVEF up to $45 \%$.

Risk factor modification is a crucial consideration in all types of $\mathrm{HF}$, and includes treatment of hypertension and prevention of myocardial ischaemia. As such, many patients with HFpEF/HFmrEF receive $A C E i / A R B$ and beta blockers.

\section{Drug therapies in the prevention of heart failure}

By modifying risk factors for $\mathrm{HF}$, the disease can be prevented or the onset delayed. Multiple trials have shown that treating hypertension can prevent HF, especially when diuretics or angiotensin-renin system inhibitors are used. ${ }^{82,83}$ The SPRINT trial assessed the benefits of a lower systolic blood pressure (BP) goal of $<120 \mathrm{mmHg} v s<140 \mathrm{mmHg}$, for older and high-risk hypertensive patients. Treating BP to the lower goal resulted in a decrease in cardiovascular disease, death and hospitalisation for HF. ${ }^{84}$ ACEi should also be used in asymptomatic patients with reduced $E F$, irrespective of comorbid hypertension, as this reduces the risk of developing symptoms of HF and associated hospitalisations. $^{35}$

The EMPA-REG OUTCOME trial assessed the impact of empaglifozin (an inhibitor of sodium-glucose cotransporter 2 ) in type 2 diabetics at high risk of cardiovascular disease as compared to placebo. Lower rates of cardiovascular and all-cause mortality, and reduction in HF hospitalisations were seen with empaglifozin. ${ }^{85}$ 


\section{Conclusion}

Heart failure is common and has an adverse prognosis. Evidence-based disease-modifying drug therapy based around neurohormonal modulation and guided by LVEF form the mainstay of therapy. Most HF patients derive symptomatic benefit from these drugs and those with HFrEF derive significant additional prognostic benefits. These therapies continue to evolve and new drugs which have emerged over recent years are being used alongside long-established ones. Contemporary management involves selecting and optimising appropriate drug regimens and, crucially, ongoing modifications to allow for the introduction of newer therapies and changing clinical status. The best outcomes are achieved when specialist teams manage these complex drug regimens, in partnership with patients, throughout the course of the disease.

\section{Conflicts of interest}

Paul R Kalra has received: research grants from Alere, Pharmacosmos and Servier; speaker fees/advisory boards/meeting support from Alere, Amgen, BMS, Janssen, Novartis, Pfizer, Pharmacosmos, Servier and Vifor.

\section{References}

1 Fox KF, Cowie MR, Wood DA et al. Coronary artery disease as the cause of incident heart failure in the population. Eur Heart J 2001;22:228-36.

2 He J, Ogden LG, Bazzano LA et al. Risk factors for congestive heart failure in US men and women: NHANES I epidemiologic follow-up study. Arch Intern Med 2001;161:996-1002.

3 Redfield MM, Jacobsen SJ, Burnett JCJr et al. Burden of systolic and diastolic ventricular dysfunction in the community: appreciating the scope of the heart failure epidemic. JAMA 2003;289:194-202.

4 Braunschweig F, Cowie MR, Auricchio A. What are the costs of heart failure? Europace 2011;13(Suppl 2):ii13-7.

5 Donkor A, McDonagh T, Hardman S. National heart failure audit April 2015 - March 2016. London: Healthcare Quality Improvement Partnership, 2017.

6 Ponikowski P, Voors AA, Anker SD et al. 2016 ESC Guidelines for the diagnosis and treatment of acute and chronic heart failure: The task force for the diagnosis and treatment of acute and chronic heart failure of the European Society of Cardiology (ESC) Developed with the special contribution of the Heart Failure Association (HFA) of the ESC. Eur Heart J 2016:37:2129-200.

7 Packer M. The neurohormonal hypothesis: a theory to explain the mechanism of disease progression in heart failure. J Am Coll Cardiol 1992:20:248-54.

8 CONSENSUS Trial Study Group. Effects of enalapril on mortality in severe congestive heart failure. Results of the Cooperative North Scandinavian Enalapril Survival Study (CONSENSUS). N Engl ] Med 1987;316:1429-35.

9 Garg R, Yusuf S. Overview of randomized trials of angiotensin-converting enzyme inhibitors on mortality and morbidity in patients with heart failure. Collaborative Group on ACE Inhibitor Trials. JAMA 1995;273:1450-6.

10 Furberg $C D$, Pitt $B$. Are all angiotensin-converting enzyme inhibitors interchangeable? J Am Coll Cardiol 2001;37:1456-60.

11 Hirooka K, Koretsune Y, Yoshimoto S et al. Twice-daily administration of a long-acting angiotensin-converting enzyme inhibitor has greater effects on neurohumoral factors than a once-daily regimen in patients with chronic congestive heart failure. J Cardiovasc Pharmacol 2004:43:56-60.
12 Cohn JN, Tognoni G, Valsartan Heart Failure Trial Investigators. A randomized trial of the angiotensin-receptor blocker valsartan in chronic heart failure. N Engl J Med 2001;345:1667-75.

13 Granger CB, McMurray J], Yusuf S et al. Effects of candesartan in patients with chronic heart failure and reduced left-ventricular systolic function intolerant to angiotensin-converting-enzyme inhibitors: the CHARM-Alternative trial. Lancet 2003;362:772-6.

14 McMurray J], Ostergren J, Swedberg K et al. Effects of candesartan in patients with chronic heart failure and reduced left-ventricular systolic function taking angiotensin-converting-enzyme inhibitors: the CHARM-Added trial. Lancet 2003;362:767-71.

15 Gheorghiade M, Bohm M, Greene S] et al. Effect of aliskiren on postdischarge mortality and heart failure readmissions among patients hospitalized for heart failure: the ASTRONAUT randomized trial. JAMA 2013:309:1125-35.

16 CIBIS-II Investigators and Committees. The Cardiac Insufficiency Bisoprolol Study II (CIBIS-II): a randomised trial. Lancet 1999:353:9-13

17 Flather MD, Shibata MC, Coats AJ et al. Randomized trial to determine the effect of nebivolol on mortality and cardiovascular hospital admission in elderly patients with heart failure (SENIORS). Eur Heart J 2005;26:215-25.

18 Krum H, Roecker EB, Mohacsi P et al. Effects of initiating carvedilol in patients with severe chronic heart failure: results from the COPERNICUS Study. JAMA 2003;289:712-8.

19 MERIT-HF Study Group. Effect of metoprolol CR/XL in chronic heart failure: Metoprolol CR/XL Randomised Intervention Trial in Congestive Heart Failure (MERIT-HF). Lancet 1999;353:2001-7.

20 Poole-Wilson PA, Swedberg K, Cleland JG et al. Comparison of carvedilol and metoprolol on clinical outcomes in patients with chronic heart failure in the Carvedilol Or Metoprolol European Trial (COMET): randomised controlled trial. Lancet 2003;362:7-13.

21 Meuwese $\mathrm{CL}$, Kirkels JH, de Jonge $\mathrm{N}$ et al. Beta-blocker therapy in unstable severe heart failure, evidence or experience? Neth Heart J 2013;21:3-5.

22 Swedberg K, Komajda M, Bohm M et al. Ivabradine and outcomes in chronic heart failure (SHIFT): a randomised placebo-controlled study. Lancet 2010;376:875-85.

23 McAlister FA, Wiebe N, Ezekowitz JA, Leung AA, Armstrong PW. Meta-analysis: beta-blocker dose, heart rate reduction, and death in patients with heart failure. Ann Intern Med 2009;150:784-94.

24 Zannad F, McMurray J], Krum $\mathrm{H}$ et al. Eplerenone in patients with systolic heart failure and mild symptoms. N Engl J Med 2011;364:11-21.

25 Pitt B, Zannad F, Remme W] et al. The effect of spironolactone on morbidity and mortality in patients with severe heart failure. Randomized Aldactone Evaluation Study Investigators. N Engl ] Med 1999;341:709-17.

26 National Institute for Health and Care Excellence. Chronic heart failure in adults: management. London: NICE, 2010.

27 Pitt B, Remme W, Zannad F et al. Eplerenone, a selective aldosterone blocker, in patients with left ventricular dysfunction after myocardial infarction. N Engl J Med 2003;348:1309-21.

28 Struthers A, Krum H, Williams GH. A comparison of the aldosterone-blocking agents eplerenone and spironolactone. Clin Cardiol 2008;31:153-8.

29 Bloch MJ, Basile JN. Spironolactone is more effective than eplerenone at lowering blood pressure in patients with primary aldosteronism. J Clin Hypertens (Greenwich) 2011;13:629-31.

30 Menown IB, Davies S, Gupta S et al. Resting heart rate and outcomes in patients with cardiovascular disease: where do we currently stand? Cardiovasc Ther 2013;31:215-23.

31 Habal MV, Liu PP, Austin PC et al. Association of heart rate at hospital discharge with mortality and hospitalizations in patients with heart failure. Circ Heart Fail 2014;7:12-20. 
32 Kalra PR, Morley C, Barnes S et al. Discontinuation of beta-blockers in cardiovascular disease: UK primary care cohort study. Int J Cardiol 2013;167:2695-9.

33 Zachariah D, Stevens D, Sidorowicz G et al. Quality of life improvement in older patients with heart failure initiated on ivabradine: results from the UK multi-centre LIVE:LIFE prospective cohort study. Int J Cardiol 2017;249:313-8.

34 McMurray J], Packer M, Desai AS et al. Angiotensin-neprilysin inhibition versus enalapril in heart failure. $N$ Engl ] Med 2014;371:993-1004.

35 Investigators SOLVD, Yusuf S, Pitt B et al. Effect of enalapril on mortality and the development of heart failure in asymptomatic patients with reduced left ventricular ejection fractions. $N$ Engl J Med 1992:327:685-91.

36 National Institute for Health and Care Excellence. Sacubitril valsartan for treating symptomatic chronic heart failure with reduced ejection fraction. London: NICE, 2016.

37 Faris R, Flather M, Purcell H et al. Current evidence supporting the role of diuretics in heart failure: a meta analysis of randomised controlled trials. Int J Cardiol 2002;82:149-58.

38 Masters ], Morton G, Anton I et al. Specialist intervention is associated with improved patient outcomes in patients with decompensated heart failure: evaluation of the impact of a multidisciplinary inpatient heart failure team. Open Heart 2017:4:e000547

39 Brater DC, Day B, Burdette A, Anderson S. Bumetanide and furosemide in heart failure. Kidney Int 1984;26:183-9.

40 Konecke LL. Clinical trial of bumetanide versus furosemide in patients with congestive heart failure. J Clin Pharmacol 1981;21:688-90.

41 Murray MD, Haag KM, Black PK, Hall SD, Brater DC. Variable furosemide absorption and poor predictability of response in elderly patients. Pharmacotherapy 1997;17:98-106.

42 Mullens W, Abrahams Z, Francis GS et al. Importance of venous congestion for worsening of renal function in advanced decompensated heart failure. J Am Coll Cardiol 2009;53:589-96.

43 Metra M, Davison B, Bettari L et al. Is worsening renal function an ominous prognostic sign in patients with acute heart failure? The role of congestion and its interaction with renal function. Circ Heart Fail 2012;5:54-62.

44 Taylor AL, Ziesche S, Yancy C et al. Combination of isosorbide dinitrate and hydralazine in blacks with heart failure. N Engl J Med 2004:351:2049-57.

45 Cohn JN, Archibald DG, Ziesche S et al. Effect of vasodilator therapy on mortality in chronic congestive heart failure. Results of a Veterans Administration Cooperative Study. N Engl J Med 1986;314:1547-52.

46 Digitalis Investigation Group. The effect of digoxin on mortality and morbidity in patients with heart failure. $N$ Engl J Med 1997:336:525-33.

47 Digitalis Investigation Group, Ahmed A, Waagstein F et al. Effectiveness of digoxin in reducing one-year mortality in chronic heart failure in the Digitalis Investigation Group trial. Am J Cardiol 2009;103:82-7.

48 Kjekshus ], Apetrei E, Barrios V et al. Rosuvastatin in older patients with systolic heart failure. N Engl J Med 2007;357:2248-61.

49 Tavazzi L, Maggioni AP, Marchioli R et al. Effect of rosuvastatin in patients with chronic heart failure (the GISSI-HF trial): a randomised, double-blind, placebo-controlled trial. Lancet 2008;372:1231-9.

50 Scirica BM, Morrow DA, Cannon CP et al. Intensive statin therapy and the risk of hospitalization for heart failure after an acute coronary syndrome in the PROVE IT-TIMI 22 study. J Am Coll Cardiol 2006;47:2326-31.

51 Tavazzi L, Maggioni AP, Marchioli R et al. Effect of n-3 polyunsaturated fatty acids in patients with chronic heart failure (the
GISSI-HF trial): a randomised, double-blind, placebo-controlled trial. Lancet 2008;372:1223-30.

52 Goldstein RE, Boccuzzi SJ, Cruess D, Nattel S. Diltiazem increases late-onset congestive heart failure in postinfarction patients with early reduction in ejection fraction. The Adverse Experience Committee; and the Multicenter Diltiazem Postinfarction Research Group. Circulation 1991;83:52-60.

53 de Vries RJ, van Veldhuisen DJ, Dunselman PH. Efficacy and safety of calcium channel blockers in heart failure: focus on recent trials with second-generation dihydropyridines. Am Heart ] 2000:139:185-94.

54 Packer M, O'Connor CM, Ghali JK et al. Effect of amlodipine on morbidity and mortality in severe chronic heart failure. Prospective Randomized Amlodipine Survival Evaluation Study Group. N Engl ] Med 1996;335:1107-14.

55 Hillege HL, Nitsch D, Pfeffer MA et al. Renal function as a predictor of outcome in a broad spectrum of patients with heart failure. Circulation 2006;113:671-8.

56 The Renal Association, British Society for Heart Failure, Think Kidneys. Changes in kidney function and serum potassium during ACEI/ARB/diuretic treatment in primary care. Think Kidneys, 2017.

57 Kotecha D, Flather MD, Altman DG et al. Heart Rate and Rhythm and the Benefit of Beta-Blockers in Patients With Heart Failure. J Am Coll Cardiol 2017:69:2885-96.

58 Van Gelder IC Groenveld HF, Crijns HJ et al. Lenient versus strict rate control in patients with atrial fibrillation. N Engl J Med 2010;362:1363-73.

59 Cullington D, Goode KM, Zhang J, Cleland JG, Clark AL. Is heart rate important for patients with heart failure in atrial fibrillation? JACC Heart Fail 2014:2:213-20.

60 Gattis WA, O'Connor CM, Leimberger JD et al. Clinical outcomes in patients on beta-blocker therapy admitted with worsening chronic heart failure. Am J Cardiol 2003;91:169-74.

61 Hunt SA, Abraham WT, Chin MH et al. ACC/AHA 2005 Guideline Update for the Diagnosis and Management of Chronic Heart Failure in the Adult: a report of the American College of Cardiology/American Heart Association Task Force on Practice Guidelines. Circulation 2005;112:e154-235.

62 Zachariah D, Taylor J, Rowell N, Spooner C, Kalra PR. Drug therapy for heart failure in older patients-what do they want? J Geriatr Cardiol 2015;12:165-73.

63 Albouaini K, Andron M, Alahmar A, Egred M. Beta-blockers use in patients with chronic obstructive pulmonary disease and concomitant cardiovascular conditions. Int J Chron Obstruct Pulmon Dis 2007;2:535-40.

64 Weitzenblum E. Chronic cor pulmonale. Heart 2003;89:225-30.

65 Morton G, Masters ], Cowburn PJ. Multidisciplinary team approach to heart failure management. Heart 2017; pii:heartjnl-2016-310598.

66 Klip IT, Comin-Colet J, Voors AA et al. Iron deficiency in chronic heart failure: an international pooled analysis. Am Heart ] 2013;165:575-82.

67 Anker SD, Comin-Colet J, Filippatos G et al. Ferric carboxymaltose in patients with heart failure and iron deficiency. $N$ Engl ] Med 2009;361:2436-48.

68 Okonko DO, Grzeslo A, Witkowski T et al. Effect of intravenous iron sucrose on exercise tolerance in anemic and nonanemic patients with symptomatic chronic heart failure and iron deficiency FERRIC-HF: a randomized, controlled, observer-blinded trial. J Am Coll Cardiol 2008;51:103-12.

69 Ponikowski P, van Veldhuisen DJ, Comin-Colet ] et al. Beneficial effects of long-term intravenous iron therapy with ferric carboxymaltose in patients with symptomatic heart failure and iron deficiencydagger. Eur Heart ] 2015;36:657-68.

70 Kalra PR. Intravenous Iron Treatment in Patients With Heart Failure and Iron Deficiency: IRONMAN. 2017 https://clinicaltrials.gov/ct2/ show/NCT02642562. 
71 Amgen. Registrational Study With Omecamtiv Mecarbil/AMG 423 to Treat Chronic Heart Failure With Reduced Ejection Fraction (GALACTIC-HF). 2017. https://clinicaltrials.gov/ct2/show/ NCT02929329.

72 Borlaug BA. The pathophysiology of heart failure with preserved ejection fraction. Nat Rev Cardiol 2014;11:507-15.

73 Kitzman DW, Little WC, Brubaker PH et al. Pathophysiological characterization of isolated diastolic heart failure in comparison to systolic heart failure. JAMA 2002;288:2144-50.

74 Edelmann F, Gelbrich G, Dungen HD et al. Exercise training improves exercise capacity and diastolic function in patients with heart failure with preserved ejection fraction: results of the Ex-DHF (Exercise training in Diastolic Heart Failure) pilot study. J Am Coll Cardiol 2011:58:1780-91.

75 Fukuta H, Goto T, Wakami K, Ohte N. Effects of drug and exercise intervention on functional capacity and quality of life in heart failure with preserved ejection fraction: A meta-analysis of randomized controlled trials. Eur J Prev Cardiol 2016;23:78-85.

76 Kitzman DW, Brubaker PH, Morgan TM, Stewart KP, Little WC. Exercise training in older patients with heart failure and preserved ejection fraction: a randomized, controlled, single-blind trial. Circ Heart Fail 2010;3:659-67.

77 Yip GW, Wang M, Wang T et al. The Hong Kong diastolic heart failure study: a randomised controlled trial of diuretics, irbesartan and ramipril on quality of life, exercise capacity, left ventricular global and regional function in heart failure with a normal ejection fraction. Heart 2008;94:573-80.

78 Bavishi C, Chatterjee S, Ather S, Patel D, Messerli FH. Beta-blockers in heart failure with preserved ejection fraction: a meta-analysis. Heart Fail Rev 2015;20:193-201.

79 Pitt B, Pfeffer MA, Assmann SF et al. Spironolactone for heart failure with preserved ejection fraction. $N$ Engl J Med 2014;370:1383-92.
80 Yusuf S, Pfeffer MA, Swedberg K et al. Effects of candesartan in patients with chronic heart failure and preserved left-ventricular ejection fraction: the CHARM-Preserved Trial. Lancet 2003:362:777-81.

81 Pieske B, Maggioni AP, Lam CSP et al. Vericiguat in patients with worsening chronic heart failure and preserved ejection fraction: results of the SOluble guanylate Cyclase stimulatoR in heArT failurE patientS with PRESERVED EF (SOCRATES-PRESERVED) study. Eur Heart J 2017:38:1119-27.

82 Kostis JB, Davis BR, Cutler ] et al. Prevention of heart failure by antihypertensive drug treatment in older persons with isolated systolic hypertension. SHEP Cooperative Research Group. JAMA 1997;278:212-6.

83 Sciarretta S, Palano F, Tocci G, Baldini R, Volpe M. Antihypertensive treatment and development of heart failure in hypertension: a Bayesian network meta-analysis of studies in patients with hypertension and high cardiovascular risk. Arch Intern Med 2011;171:384-94.

84 SPRINT Research Group, Wright JT Jr, Williamson JD et al. A Randomized Trial of Intensive versus Standard Blood-Pressure Control. N Engl J Med 2015;373:2103-16.

85 Zinman B, Wanner C, Lachin JM et al. Empagliflozin, Cardiovascular Outcomes, and Mortality in Type 2 Diabetes. N Engl J Med 2015:373:2117-28.

Address for correspondence: Dr Paul R Kalra, Department of Cardiology, Portsmouth Hospitals NHS Trust, Southwick Hill Road, Cosham, Portsmouth PO6 3LY, UK.

Email: paulkalra@doctors.org.uk

\section{Royal College of Physicians}

\section{Quacks, rogues and charlatans}

Quacks, rogues and charlatans takes the reader on a lively tour of colourful characters and dubious cures that have littered the Royal College of Physicians' 500-year history.

Order by phone or online

Tel +44 (0)20 30751358

or visit www.rcplondon.ac.uk/shop
Price: $£ 12$

(Postage and packaging not included)

$10 \%$ discount for fellows and members,

$15 \%$ discount for foundation doctors and students 